\title{
Determining spatial and temporal overlap of an endangered seabird with a large commercial trawl fishery
}

\author{
Stephani G. Zador ${ }^{1,3, *}$, Julia K. Parrish ${ }^{1,2}$, André E. Punt ${ }^{1}$, Jennifer L. Burke ${ }^{1}$, \\ Shannon M. Fitzgerald ${ }^{3}$
}

\author{
${ }^{1}$ Box 355020, School of Aquatic and Fishery Sciences, University of Washington, Seattle, Washington 98195, USA \\ ${ }^{2}$ Box 351800, Department of Biology, University of Washington, Seattle, Washington 98195, USA \\ ${ }^{3}$ NOAA Fisheries, Alaska Fisheries Science Center, 7600 Sand Point Way NE, Bldg. 4, Seattle, Washington, 98115, USA
}

\begin{abstract}
Spatial and temporal overlap between the short-tailed albatross Phoebastria albatrus, an endangered species, and the Alaskan groundfish trawl fleet is of concern because of the potential for incidental mortality. Due to the small size of this albatross population (ca. 2000 birds) and their wide-ranging foraging behavior, opportunistic sightings contribute the majority of the data on their distribution. In contrast, detailed information exists on fishing effort. In this study, 2 methods were used to predict albatross distributions: (1) bounded interpolation of sightings and (2) distance to the $1000 \mathrm{~m}$ isobath. The fishery was grouped into 5 sectors based on fish processing mode and predominant product type. Locations and durations of observed trawls were associated with the predicted albatross densities and overlap was quantified using 2 metrics. Spatial and temporal overlap of albatrosses and the trawl fleet was influenced by the assumptions used to infer albatross distribution and also differed among trawl sectors depending on the metric used to calculate overlap. The sectors with the highest and lowest overlap changed seasonally. In general, overlap scores were lowest in winter and spring due to both low trawl effort (in winter) and low albatross sightings (winter and spring). Relative effort in trawl sectors, in addition to proximity to high predicted albatross densities, contributed to overlap rankings such that some sectors with greater effort in areas with lower predicted albatross density had higher overlap scores than sectors with less effort in areas with high predicted albatross densities.
\end{abstract}

KEY WORDS: Short-tailed albatross · Phoebastria albatrus · Alaska · Trawl · Spatial overlap · Temporal overlap · Risk analysis

Resale or republication not permitted without written consent of the publisher

\section{INTRODUCTION}

Ecosystem-based fishery management propounds that commercial fisheries should be managed for sustainability of the target species as well as for indirect and inadvertent impacts on non-target species and habitat (Pikitch et al. 2004). Bycatch, defined as incidental mortality of non-target species due to fishing activity, is of particular management concern when fisheries occur within the habitats of threatened and endangered species (Hall 1996). An integral component of managing for non-target species in an eco- system-based framework is to understand the extent of spatial and temporal overlap of the species of concern and the target fishery. Overlap is not necessarily predictive of interactions, but is a precondition. Where the extent of overlap is well known, appropriate management measures can be crafted to reduce the potential for negative interactions. For example, in New Zealand, knowledge of the limited distribution of the critically endangered Maui's dolphin Cephalorhynchus hectori prompted the closure of a gillnet fishery within a 210 nautical mile stretch of coastline (Slooten et al. 2006). However, lack of such knowledge can leave the 
species of concern unprotected, a situation that Troëng et al. (2004) address when emphasizing the need for quantifying the overlap between critically endangered leatherback sea turtles Dermochelys coriacea and fishing effort. From a fisheries management point of view, specific knowledge of the spatial and temporal distribution of species of concern can also prevent overly precautionary closures (i.e. closures of vast areas).

Albatrosses are wide-ranging, long-lived predators whose foraging ranges overlap with the pelagic, slope, and shelf habitats used by many fisheries (Croxall \& Wood 2002, Birdlife International 2004). Many albatross species are attracted to fishing vessels as a source of food, including bait, discards, and processing waste (Bartle 1991). Once at the vessel, albatrosses can become hooked on longline gear, entangled in nets, or injured (including lethally) by collisions with trawl cables while attempting to forage (Weimerskirch et al. 2000, Nel et al. 2002, Gonzalez-Zevallos \& Yorio 2006). This interaction is pervasive enough that albatross population declines have been attributed to incidental mortality in commercial fisheries (Weimerskirch et al. 1997).

The endangered short-tailed albatross Phoebastria albatrus, although few in number (ca. 2000 individuals), occurs within the same waters as the vast Alaska groundfish trawl fishery, in which the catch of one of the target species, walleye pollock Theregra chalcogramma, is the second largest in tons among all fisheries (FAO 2004). A value representing the 'expected take' (incidental mortality) of short-tailed albatrosses in this fishery has been designated under the guidelines of the US Endangered Species Act (USFWS 2003). Given this designation, if 2 trawl-related mortalities occur in any 5 yr period, the National Marine Fisheries Service must initiate an Endangered Species Act consultation with results that could range from an increase in the designated 'expected take,' thereby removing the need for further action, to closure of the fishery.

Incidental mortality of albatrosses due to trawl gear has been well documented in the Southern Ocean (Gonzalez-Zevallos \& Yorio 2006, Sullivan et al. 2006). Although no incidental mortalities of short-tailed albatrosses due to trawl gear have been reported within the Alaska groundfish trawl fishery, the possibility that one (or more) mortalities have been unreported or unidentified is supported by documented mortalities of co-occurring Laysan albatross Phoebastris immutabilis by trawl gear (Wilson et al. 2004) and 6 documented short-tailed albatross mortalities in North Pacific longline gear (USFWS 2005). In addition, the likelihood of interaction with North Pacific fisheries is also rising as the short-tailed albatross population is rapidly increasing ( $7 \%$ annually; USFWS 2005, Zador et al. 2008).

The goal of this study was to quantify the extent of spatial and temporal overlap between a non-target species of management concern for which data on abundance is based on incidental sightings, and a fishery for which detailed information on effort is available. The methods were applied to the case of the short-tailed albatross and the Alaska groundfish trawl fishery to determine the relative overlap among sectors of this fishery and the distribution of albatrosses. We considered alternative methods for calculating the spatial distribution of albatrosses and alternative metrics for quantifying the risk of a possible fishery-seabird interaction, given uncertainties in the data.

\section{MATERIALS AND METHODS}

Trawl data. The Fisheries Monitoring and Analysis division of the Alaska Fisheries Science Center, NOAA Fisheries, places certified observers aboard commercial fishing vessels in the Gulf of Alaska, Aleutian Islands, and Bering Sea to collect data for scientific, management, regulation, and compliance purposes (AFSC 2005a). Observer coverage is based on vessel size and gear type, and the selection of observed hauls and samples within the hauls are randomized. Trawl vessels make up the largest portion of commercial fishing vessels that carry observers, the remainder being longline and pot vessels (AFSC 2005a). Trawl vessels $\geq 125 \mathrm{ft}$ $(38.1 \mathrm{~m})$ long are required to carry an observer whenever groundfish are being taken in the Exclusive Economic Zone off Alaska, vessels 60 to $124 \mathrm{ft}$ (18.3 to $37.8 \mathrm{~m}$ ) long must carry an observer for $30 \%$ of their fishing days within each calendar quarter, and vessels $<60 \mathrm{ft}(18.3 \mathrm{~m})$ are not required to carry observers and are consequently not included in this analysis. Observers are not stationed within view of, and therefore cannot record, potential seabird-trawl interactions. The locations and durations of observed trawls from 1999 to 2005 were used to determine the spatial and temporal distribution of deployed gear. This period was chosen to reflect the current fishery patterns established after the passage of the American Fisheries Act, which in October 1998 led to a reorganization of the Bering Sea/ Aleutian Island pollock fleet (NPFMC 2002).

The Alaska groundfish trawl fleet was subdivided into sectors due to its size and the diversity of operations among vessels, and to assess the relative overlap of each sector with the distribution of short-tailed albatrosses. The vessels can be grouped by multiple factors, including size, processing mode, fishing gear, onboard equipment, ownership associations, target species, single or multiple target operations, and legal frameworks. These vessel differences may affect attractiveness to seabirds and pose different degrees of risk to seabirds attending fishing operations. However, splitting the fishery into many fine-scale sectors can 
create an overly complex analysis that is less useful for policy and ecosystem management decisions. Instead, trawl vessels were classified into 5 sectors based primarily on processing modes and predominant product type, and the scheme used by AFSC (2005b) (Table 1). The sectors were not defined using target species alone because processing mode and product type were assumed to have a greater influence on determining potential albatross interactions with vessels than target species and because trawl vessels can sometimes participate in more than one target fishery. Sectors can be amalgamated into 2 broad groups based on harvesting and processing operations: catcher-processors (CPs) and catcher vessels (CVs). CPs catch and process fish on board so that the product delivered ranges from minimally processed headed-and-gutted fish to more fully processed fillets, surimi (processed fish paste used to produce imitation crab meat and other products), and fishmeal. On CVs, fish are caught and delivered whole to at-sea or shore-based processors. The 3 CP sectors were defined by predominant product type and degree of processing; the $2 \mathrm{CV}$ sectors were defined by the fishing activities in a given year (Table 1). In some cases, individual vessels belonged to different sectors in different years.
Albatross data. We used 2 sources of data to determine short-tailed albatross distribution within the range of the Alaskan trawl fleet: a USGS/USFWS database of incidental sightings of short-tailed albatrosses at sea (NPPSD 2005) and independent observations of short-tailed albatrosses made by G. Hunt and co-workers on survey transects along the Aleutians and across the southeast Bering Sea (G. Hunt unpubl. data). Observations in the USGS/USFWS database were made by fishers, fisheries observers, biologists, and birdwatchers while aboard vessels of opportunity. Seventy-nine percent of the observations were from fishing vessels, $17 \%$ from research vessels and the remaining from other or unknown platforms. These data do not include effort (i.e. amount of time or locations where observers looked for short-tailed albatrosses), so absolute albatross abundance cannot be calculated using these data. However, the restricted distribution of albatross sightings in contrast to the known general travel patterns of some of the vessels of opportunity suggests that the data are sufficient to describe qualitatively albatross distributional patterns and pelagic habitat preferences (Piatt et al. 2006).

The location coordinates of all albatross sightings were mapped using ArcGIS 9.1 (ESRI 2005). Sightings

Table 1. Descriptions of trawl sectors used in this analysis. GOA: Gulf of Alaska; BSAI: Bering Sea and Aleutian Islands

\begin{tabular}{|c|c|c|c|}
\hline Sector & Definition & Offal discharge & Description \\
\hline \multicolumn{4}{|c|}{ Catcher-Processor vessels } \\
\hline PollockCP-Meal & $\begin{array}{l}\text { Pollock trawl catcher-processors } \\
\geq 125 \mathrm{ft}(38.1 \mathrm{~m}) \text { in length with } \\
\text { fish meal plants }\end{array}$ & Yes, minimal & $\begin{array}{l}\text { Large factory trawlers focusing almost } \\
\text { exclusively on surimi production in } \\
\text { the BSAI pollock fishery }\end{array}$ \\
\hline PollockCP & $\begin{array}{l}\text { Pollock trawl catcher-processors } \\
\geq 125 \mathrm{ft}(38.1 \mathrm{~m}) \text { in length without } \\
\text { fish meal plants }\end{array}$ & Yes & $\begin{array}{l}\text { Large factory trawlers focusing on } \\
\text { surimi and fillet production in the } \\
\text { BSAI pollock fishery }\end{array}$ \\
\hline DiverseCP & $\begin{array}{l}\text { Head-and-gut trawl catcher- } \\
\text { processors }>60 \mathrm{ft}(18.3 \mathrm{~m}) \text { in length }\end{array}$ & Yes & $\begin{array}{l}\text { Medium to large factory trawlers } \\
\text { that primarily produce headed and } \\
\text { gutted products from Pacific cod, } \\
\text { flatfish, Atka mackerel, and rockfish } \\
\text { caught in the BSAI and GOA }\end{array}$ \\
\hline \multicolumn{4}{|l|}{ Catcher vessels } \\
\hline PollockCV & $\begin{array}{l}\text { Bering Sea pollock trawl catcher } \\
\text { vessels }>60 \mathrm{ft}(18.3 \mathrm{~m}) \text { in length }\end{array}$ & No & $\begin{array}{l}\text { Medium to large vessels that rely } \\
\text { almost exclusively on pollock } \\
\text { harvested in the Bering Sea. The } \\
\text { catch is delivered to Bering Sea } \\
\text { shoreplants, motherships, or } \\
\text { catcher-processors }\end{array}$ \\
\hline DiverseCV & $\begin{array}{l}\text { Diverse target trawl catcher } \\
\text { vessels } 60-124 \mathrm{ft}(18.3-37.8 \mathrm{~m}) \\
\text { in length }\end{array}$ & No & $\begin{array}{l}\text { Medium-sized vessels that participate } \\
\text { in the GOA and BSAI pollock and } \\
\text { Pacific cod fisheries. Some vessels } \\
\text { may also participate in the halibut } \\
\text { individual fishing quota fisheries } \\
\text { using longline gear }\end{array}$ \\
\hline
\end{tabular}


were classified by season (winter: December, January, February; spring: March, April, May; summer: June, July, August; fall: September, October, November) and combined across years due to small sample sizes. Seasonally binned 1999 to 2005 data were used to predict the spatial distribution of albatross during the same time period and spatial extent as the Alaska groundfish trawl fleet. Inference about overlap between albatrosses and fisheries depends critically on the assumptions used to determine albatross distribution (Tuck et al. 2001), so we chose to compare and contrast 2 methods for describing the seasonal distribution of shorttailed albatrosses: distance-weighted interpolation of sightings (spatial interpolation) and a more general model of distance from the $1000 \mathrm{~m}$ isobath (bathymetric contour).

For the spatial interpolation method, albatross sightings were interpolated using inverse distance weighting. Inverse distance weighting is advantageous over other interpolation methods because the range of output values is restricted to the range of the input values. The interpolation was bounded to prevent estimation across areas of known low albatross abundance, such as the waters overlying abyssal depths in the Bering Sea (Suryan et al. 2006). The boundary of the interpolation was derived from $2 \mathrm{~min}(1 \mathrm{~min}=$ $1.852 \mathrm{~km}$ ) gridded bathymetric data with a vertical datum referenced to mean sea level (ETOPO2 2001) for the North Pacific and Bering Sea. The interpolation boundary was established between shore and $2000 \mathrm{~m}$ depth to encompass a majority of the sightings while allowing for a gradual decline in predicted values towards the boundary. The boundary line was simplified at $30 \mathrm{~km}$ simplification tolerance for vertices. Observations were binned into $30 \mathrm{~km}^{2}$ grid cells because albatross sightings were originally recorded with variable spatial precision. Lack of positive sightings in opportunistic data does not imply absence. Therefore, rather than assume zero albatross for all cells with no sighting, a $90 \mathrm{~km}$ buffer was created around the aggregated sightings and a 0 value was added every $90 \mathrm{~km}$ outside the buffer. Inverse distance weighting was performed using the nearest 12 sample points at a power of 2 to interpolate abundance at a resolution of $10 \mathrm{~km}^{2}$ (cell size). Values presented in figures were scaled to the highest value across seasons to simplify comparisons.

Short-tailed albatrosses are known to associate with bathymetric shelf break and slope habitats (Suryan et al. 2006).
Indeed, $88 \%$ of the opportunistic albatross sightings were within $30 \mathrm{~km}$ of the $1000 \mathrm{~m}$ isobath, which we considered to be the margin between shelf break and slope (Yen et al. 2004) (Fig. 1). Therefore, we chose to use bathymetry as a proxy for predicting albatross distribution as an alternative to the spatial interpolation method. For the bathymetric contour method, multiple ring buffers were created every $30 \mathrm{~km}$ from the $1000 \mathrm{~m}$ isobath out to $810 \mathrm{~km}$, well beyond the range of the Alaskan groundfish trawl fishery and most sightings. For each season, the total number of albatross sightings within each buffer was fit to an exponential model,

$$
N_{d}=N_{0}\left(\delta+\mathrm{e}^{r d}\right)
$$

where $d$ is the distance from the $1000 \mathrm{~m}$ isobath, $N_{0}$ is the estimated number at the $1000 \mathrm{~m}$ isobath, $r$ is the estimated rate of decline, and $\delta$ is a parameter to represent the background density of albatrosses. The values for the parameters of Eq. (1) were estimated under the assumption that the observations (numbers per 30 $\mathrm{km}$ buffer) were Poisson-distributed. This model was used to infer the albatross density in the middle of each $30 \mathrm{~km}$ buffer (Fig. 2). These values were then scaled to the highest value per buffer across seasons to simplify comparisons. Opportunistic sightings of albatrosses were more prevalent on the shallow side of the $1000 \mathrm{~m}$ isobath (Piatt et al. 2006); however, the vast majority of vessel traffic was also on the shallow side of the isobath. Therefore because of the likely unequal observation effort and the lack of any significant preference seen in satellite-tagged short-tailed albatrosses for the

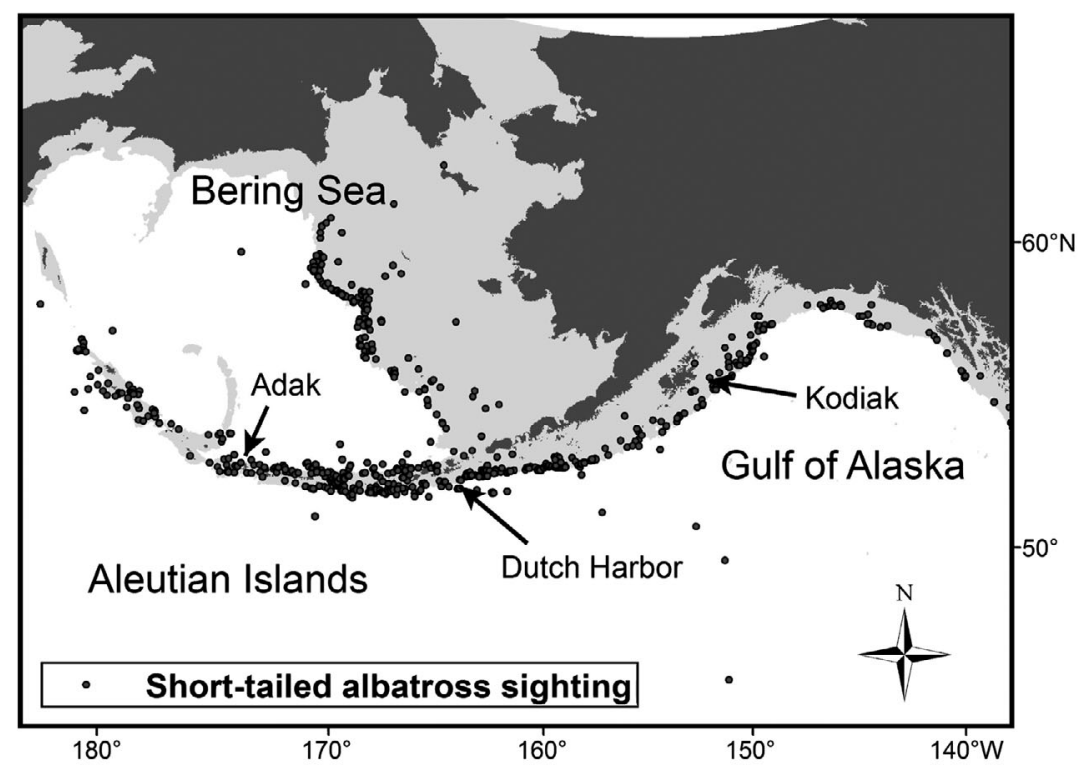

Fig. 1. Phoebastria albatrus. Sightings in study area, all seasons, 1999-2005. Gray shading indicates depths $<1000 \mathrm{~m}$ 

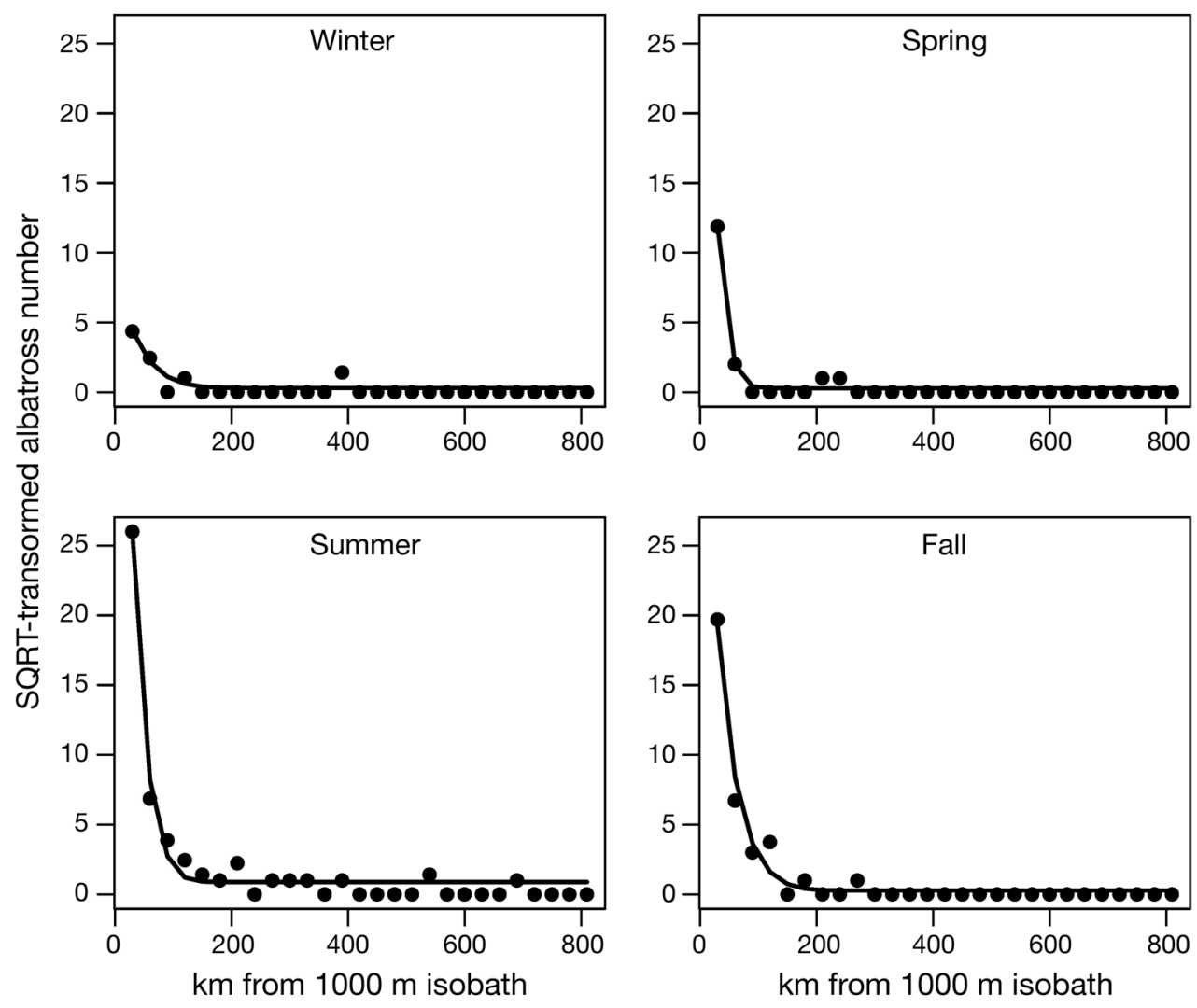

Fig. 2. Phoebastria albatrus. Square-root transformed short-tailed albatross counts and model predictions using the bathymetric contour method

shallow or abyssal side of the shelf break and slope habitat (Suryan et al. 2006, Suryan et al. 2007), we assumed that relative density decreased based on distance from the $1000 \mathrm{~m}$ isobath regardless of the depth under the sighting.

Determining relative overlap among trawl sectors. Each trawl was associated with a predicted relative albatross density based on the location of trawl retrieval and the predicted distribution of albatrosses based on each of the spatial interpolation and bathymetric contour methods. This enabled the overlap calculations to reflect the true distribution of the vessels rather than assume fishery effort to be equal across a pre-defined area such as a fishery-management unit. We chose to use the location of trawl retrieval rather than initial deployment, or an interpolated midpoint, because vessel tracks are often not linear during gear deployment (S. Fitzgerald pers. obs.) and some seabirds are attracted to the net as it nears the vessel (Gonzalez-Zevallos \& Yorio 2006).

The risk of interaction between albatrosses and trawl gear is likely influenced by the total time of gear deployment. Therefore, account was taken of trawl duration when characterizing relative overlap. Two measures of relative overlap were used: (1) the mean overlap score, which measures the predicted overlap for each unit of trawl duration,

$$
\sum_{a} B_{a} T_{a} / \sum_{a} T_{a}
$$

where $B_{a}$ is the predicted relative albatross density corresponding to the $a^{\text {th }}$ trawl made by the sector concerned, and $T_{a}$ is the length of the $a^{\text {th }}$ trawl in min; and (2) the sum overlap score, which measures the overlap given the total trawling effort of a sector, and is the numerator of Eq. (2).

The sum overlap scores for sectors with vessels $<125 \mathrm{ft}$ ( $38.1 \mathrm{~m})$ were expanded by a factor of 3.3333 to reflect the $30 \%$ observer coverage; the calculation of mean overlap scores are not influenced by observer coverage. Two additional metrics are presented for the spatial interpolation method: the percent of trawl minute that (1) were in areas of zero predicted albatross density and (2) comprised $80 \%$ of the sum overlap score. These metrics were not calculated for the bathymetric contour method because the predicted albatross densities were derived from continuous distributions. This meant that the bathymetric contour method predicted birds in areas with shelf and slope areas, but which are not frequented by the Alaska groundfish trawl fishery. However, this did not affect overlap 
scores, as they were calculated by the predicted albatross density per actual trawl location only. The relative overlap scores are not directly comparable across the 2 methods to predict albatross distribution, so we discuss their relative values.

\section{RESULTS}

\section{Trawl fishery}

The characterization of the trawl fishery reflected differences among sectors in fishing effort, amount and type of discharge, and when fishing occurs seasonally. In total, CVs spent more hours fishing than CPs (617 262 versus 504 796), with a smaller difference during summer (Table 2). This difference was driven by consistently fewer vessels and lower effort in the PollockCP and PollockCP-Meal sectors (refer to Table 1 for definition of vessel types), and high numbers of vessels and effort in the PollockCV sector across much of the year. The CP vessels were also distinguished from CVs by their discharge of processing waste, or offal. The

Table 2. Trawl effort recorded by fisheries observers. Total number of hours trawled were extrapolated to account for the $30 \%$ observer coverage on vessels in sectors DiverseCP, PollockCV, and DiverseCV (see Table 1 for definitions)

\begin{tabular}{|c|c|c|c|c|}
\hline $\begin{array}{l}\text { Season } \\
\text { Sector }\end{array}$ & $\begin{array}{c}\text { Total no. } \\
\text { of observed } \\
\text { trawl locations }\end{array}$ & $\begin{array}{l}\text { Trawls with } \\
\text { duration } \\
\text { recorded (\%) }\end{array}$ & $\begin{array}{c}\text { No. of } \\
\text { vessels }\end{array}$ & $\begin{array}{c}\text { Total no. of } \\
\text { hours trawled }\end{array}$ \\
\hline \multicolumn{5}{|l|}{ Winter } \\
\hline PollockCP-Meal & 5245 & 98.0 & 9 & 19502 \\
\hline PollockCP & 4575 & 95.6 & 9 & 16625 \\
\hline DiverseCP & 8053 & 96.5 & 24 & 66513 \\
\hline PollockCV & 8165 & 96.7 & 92 & 76332 \\
\hline \multirow[t]{2}{*}{ DiverseCV } & 2800 & 90.2 & 80 & 59232 \\
\hline & & & Total & 238204 \\
\hline \multicolumn{5}{|l|}{ Spring } \\
\hline PollockCP-Meal & 4803 & 98.0 & 9 & 16438 \\
\hline PollockCP & 3845 & 92.0 & 9 & 13564 \\
\hline DiverseCP & 20489 & 96.3 & 24 & 110542 \\
\hline PollockCV & 7212 & 95.1 & 93 & 87694 \\
\hline \multirow[t]{2}{*}{ DiverseCV } & 4352 & 95.0 & 79 & 89958 \\
\hline & & & Total & 318196 \\
\hline \multicolumn{5}{|l|}{ Summer } \\
\hline PollockCP-Meal & 7576 & 97.9 & 8 & 26329 \\
\hline PollockCP & 6562 & 93.4 & 7 & 22190 \\
\hline DiverseCP & 19114 & 97.9 & 23 & 103513 \\
\hline PollockCV & 8471 & 96.7 & 90 & 102583 \\
\hline \multirow[t]{2}{*}{ DiverseCV } & 3676 & 91.8 & 73 & 52944 \\
\hline & & & Total & 307559 \\
\hline \multicolumn{5}{|l|}{ Fall } \\
\hline PollockCP-Meal & 4575 & 96.8 & 8 & 19771 \\
\hline PollockCP & 3025 & 93.6 & 7 & 13938 \\
\hline DiverseCP & 11586 & 96.3 & 24 & 75871 \\
\hline PollockCV & 7337 & 95.7 & 89 & 102788 \\
\hline \multirow[t]{2}{*}{ DiverseCV } & 2321 & 90.0 & 74 & 45731 \\
\hline & & & Total & 258099 \\
\hline
\end{tabular}

type of discharge varied among CP sectors, with potential consequences for relative bird attraction. DiverseCP vessels processed catch minimally, mincing heads and entrails before discharging them. In contrast, PollockCP and PollockCP-Meal vessels processed catch more fully, discharging offal after fillet and surimi production. The amount of particulate fish material in the offal from PollockCP-Meal vessels was most reduced relative to vessels in other sectors due to higher utilization of the catch in the onboard fishmeal plants.

Across all sectors, trawling effort was lowest and had the most restricted distribution during winter, and the opposite was true in the spring (Fig. 3, Table 2). Seasonal patterns in the spatial distribution of the trawl fishery primarily reflected the underlying regulatory framework and shifting target species. Most vessels targeting pollock followed a general pattern of fishing in the southern end of the Bering Sea shelf during winter and spring, then expanding north along the shelf break during summer and fall. Effort was especially concentrated along shelf breaks during summer in both the Bering Sea and Gulf of Alaska. The DiverseCP sector was the most geographically diverse, fishing the Aleutians, nearshore Gulf of Alaska, and Bering Sea shelf and shelf break. Total fishing effort was most widely distributed during the summer, with the effort during winter most concentrated on the southern Bering Sea shelf. The DiverseCV sector was the most portassociated, fishing near Dutch Harbor, Kodiak, and Adak.

\section{Albatross distribution}

The spatial interpolation method indicated that densities were lowest and most confined during winter, when most adult albatrosses were at the breeding colonies, then increased and expanded north and west during spring and summer (Fig. 4a-d). Peak densities occurred during summer and distributions became most concentrated along shelf breaks during fall. Areas of high concentrations (hotspots) occurred in the central Aleutians and along the northern Bering Sea shelf break during summer and fall, creating discontinuous sections of high and low densities generally associated with the shelf break.

The bathymetric contour method described bands of equal distribution 

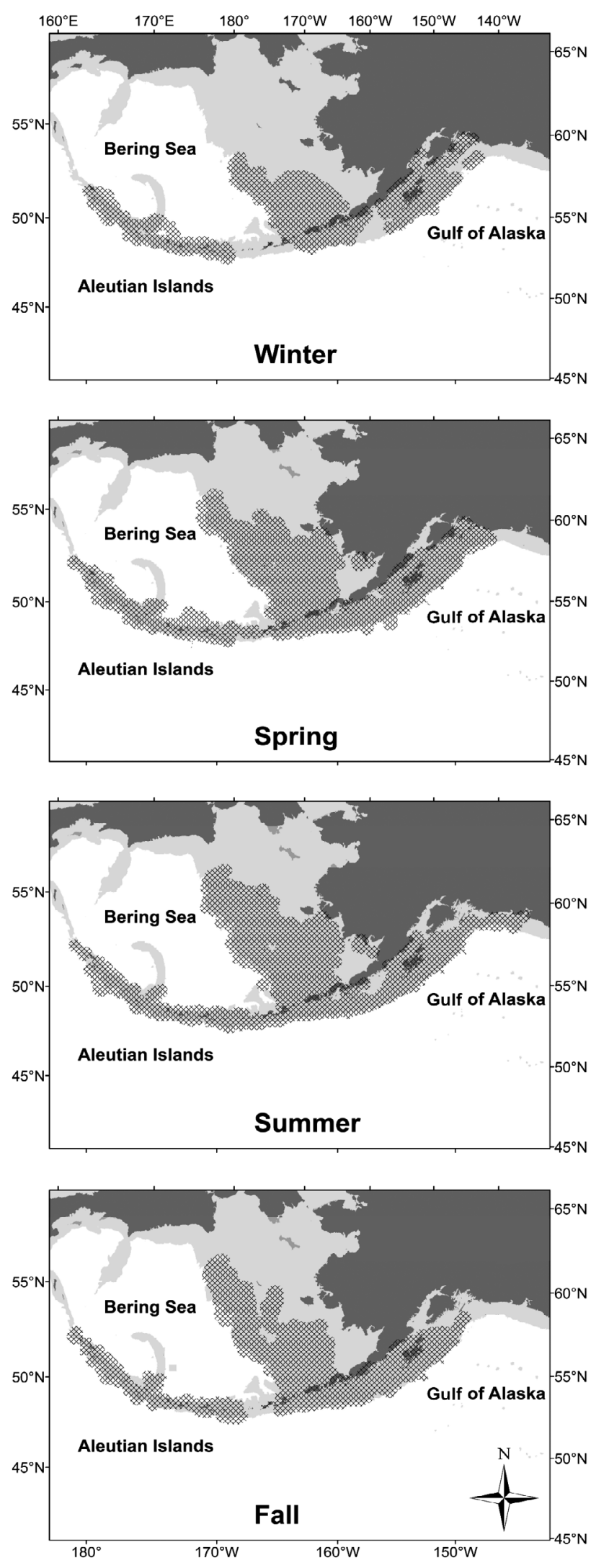

Fig. 3. Spatial coverage of trawl fishing during winter, spring, summer, and fall as a function of distance from the $1000 \mathrm{~m}$ isobath (Fig. $4 \mathrm{e}-\mathrm{h}$ ), smoothing out both peak values and missing data cells that affected the spatial interpolation method. The highest densities occurred within $30 \mathrm{~km}$ of the $1000 \mathrm{~m}$ isobath in all seasons, with summer having the highest relative density within this range (Fig. 4). The influence of single, remote sightings was minimized using this method.

\section{Relative overlap among trawl sectors}

General patterns of overlap among trawl sectors were sensitive to how albatross distribution was characterized (Fig. 5, Appendix). Higher mean overlap scores as determined by the spatial interpolation method reflected effort concentration near areas that had sightings of very high concentrations of albatrosses. For example, trawl effort near an albatross hotspot, based on a sighting of 136 birds just off the shelf break in the northern Bering Sea during fall (Piatt et al. 2006), contributed exceptionally high scores for each trawl minute in that area such that only $30 \%$ of trawl minutes were required to achieve $80 \%$ of the sum overlap score for the DiverseCP sector (Table 3). In contrast, high mean overlap scores as determined by the bathymetric contour method reflected high sector effort near shelf breaks, but not necessarily near albatross hotspots (e.g. the PollockCP sector during summer). For both methods, sum overlap scores were correlated with their corresponding mean overlap scores, but were also impacted by the total effort (trawling time) within a sector. Thus, it was possible for a sector in an area of relatively moderate predicted albatross density to have a high sum overlap score if effort was high relative to other trawl sectors (e.g. the DiverseCP sector in spring and summer using the bathymetric contour method). Characterization of the potential for interaction between a trawl sector and albatrosses using only mean or sum overlap scores must therefore be interpreted with caution.

Despite general differences in effort (higher among CVs in all seasons), neither the spatial interpolation nor bathymetric contour method returned a consistent pattern in overlap scores between CPs and CVs (Fig. 5, Appendix). Rather than a single sector predominating, the sectors with the highest overlap changed seasonally. For example, the PollockCP sectors were among those with the highest mean overlap scores during summer and fall, but had the lowest scores using the spatial interpolation method during winter and spring. There was some seasonal concordance in mean overlap scores. During summer, both methods returned higher mean scores for the PollockCP sectors and lower mean scores for the catcher vessel sectors. Dur- 

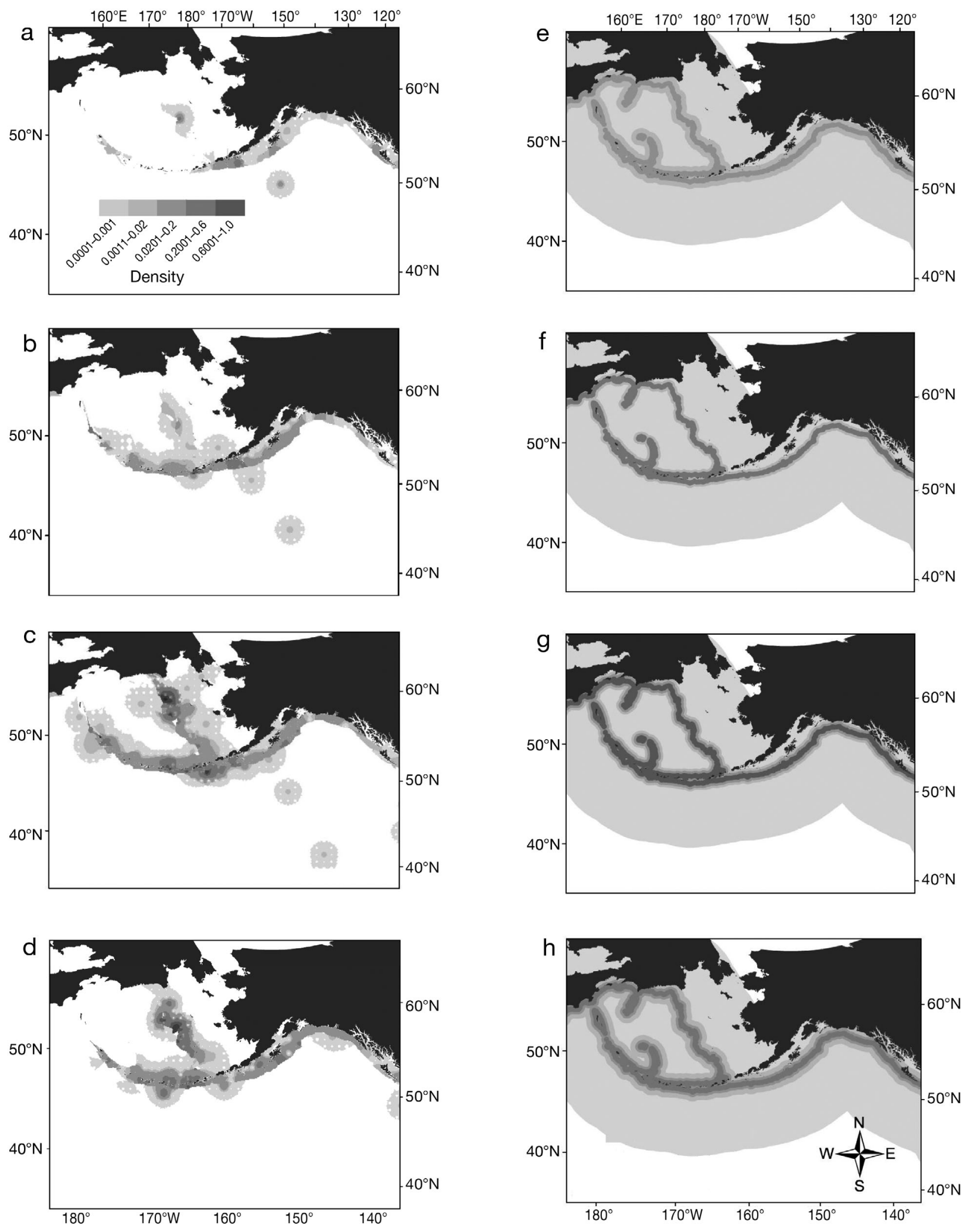

Fig. 4. Phoebastria albatrus. Distribution of short-tailed albatrosses as predicted using the spatial interpolation method during (a) winter, (b) spring, (c) summer, and (d) fall, and the bathymetric contour method during (e) winter, (f) spring, (g) summer, and (h) fall. Relative albatross densities are scaled to the highest value across seasons for each method to enable comparisons 

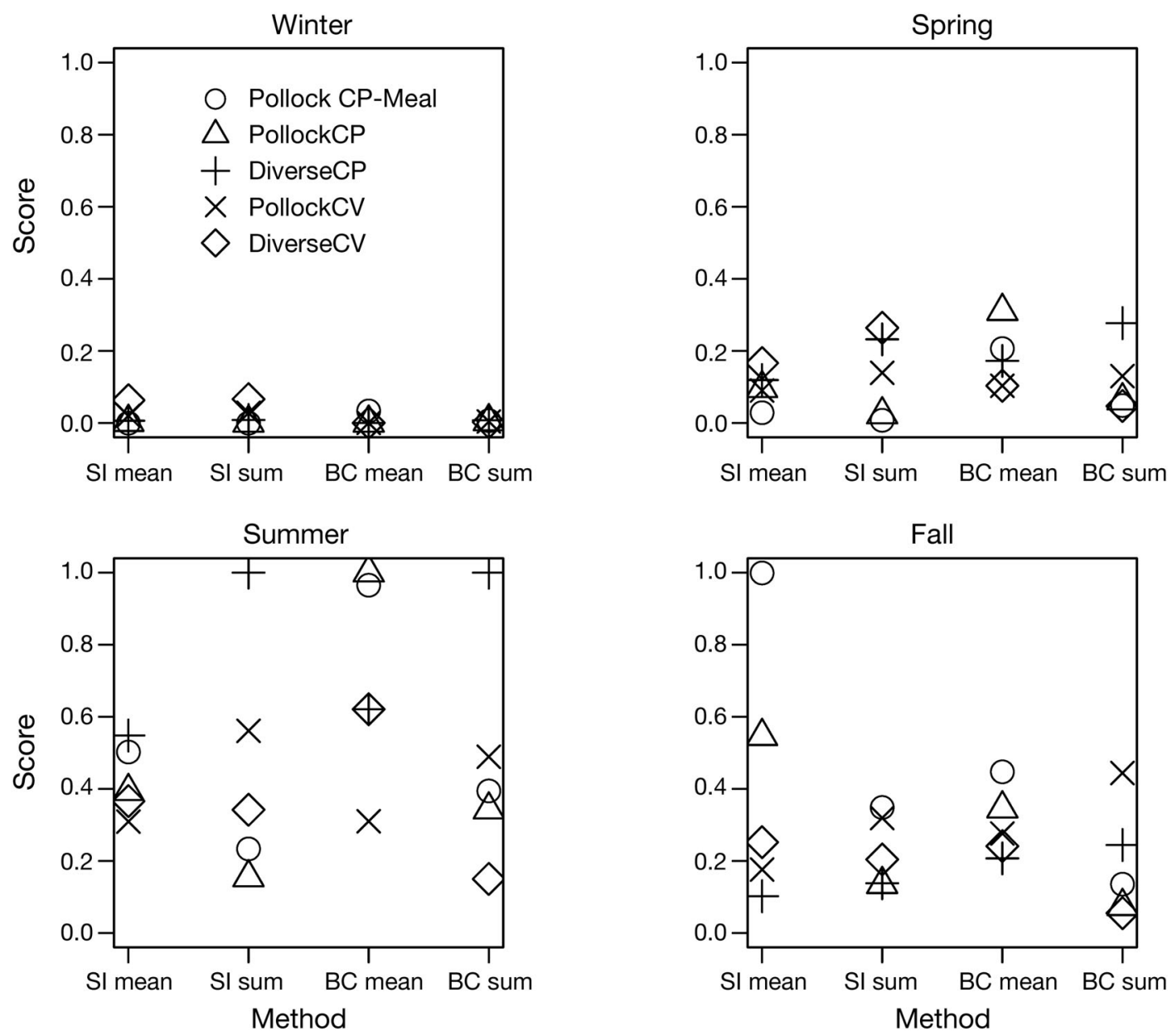

Fig. 5. Comparison of overlap scores among seasons, trawl sectors, and methods. SI mean and SI sum are, respectively, the mean and sum overlap scores calculated using the spatial interpolation method. BC mean and BC sum are, respectively, the mean and sum overlap scores calculated from using the bathymetric contour method. Overlap scores have been standardized to enable comparisons

ing spring and summer, the DiverseCP sector had the highest or second-highest sum overlap score due to the high effort in this sector. During fall, the PollockCP sectors had the highest mean scores using both methods to predict albatross distribution. In general, overlap scores were lowest in winter and spring due to both low trawl effort (in winter) and low albatross sightings (winter and spring).

The sectors with the least overlap, and therefore potentially least in danger of interacting with albatrosses, are also of great interest. During summer and fall, the mean overlap scores for the PollockCV sector are among the lowest, although the opposite is true for their sum overlap scores, given the high fishing effort by this sector. The sum overlap scores using both methods were among the lowest for the PollockCP sector, reflecting the small number of vessels in this sector. The DiverseCV sector had the lowest mean and sum overlap scores using the bathymetric contour method and moderate to low overlap scores using the spatial interpolation method, indicating that relatively more trawling in this sector was done away from the shelf break and albatross hotspots.

\section{DISCUSSION}

In the Alaska groundfish trawl fishery, there was year-round overlap with short-tailed albatross distribution. However, the sectors with the highest and lowest overlap scores differed as a function of season, method used to predict albatross distribution, and metrics used to calculate overlap. In the absence of data on wandering albatross Diomedea exulans distribution, Tuck et al. (2001) contrasted assessments of longline fishery interactions based on 2 hypotheses about albatross distribution: a worst-case scenario, with distribution proportional to the distribution of the fishery, and a null 
Table 3. Percent of trawl minutes with zero overlap and the minimum number of minutes to achieve $80 \%$ of the sum overlap score as calculated from the overlap of trawls with albatross distributions predicted using the spatial interpolation method (see Table 1 for definitions)

\begin{tabular}{|lcc|}
\hline $\begin{array}{l}\text { Season } \\
\text { Trawl sector }\end{array}$ & $\begin{array}{c}\text { Trawl minutes } \\
\text { with 0 score (\%) }\end{array}$ & $\begin{array}{c}\text { Minimum minutes } \\
\text { to achieve 80\% } \\
\text { of sum score (\%) }\end{array}$ \\
\hline Winter & & \\
PollockCP-Meal & 93 & 2 \\
PollockCP & 93 & 3 \\
DiverseCP & 93 & 2 \\
PollockCV & 73 & 13 \\
DiverseCV & 42 & 31 \\
Spring & & \\
PollockCP-Meal & 35 & 21 \\
PollockCP & 18 & 30 \\
DiverseCP & 24 & 25 \\
PollockCV & 6 & 43 \\
DiverseCV & 4 & 53 \\
Summer & & \\
PollockCP-Meal & 0 & 54 \\
PollockCP & 0 & 69 \\
DiverseCP & 10 & 20 \\
PollockCV & 0 & 71 \\
DiverseCV & 1 & 67 \\
Fall & & 38 \\
PollockCP-Meal & 0 & 35 \\
PollockCP & 0 & 30 \\
DiverseCP & 4 & 47 \\
PollockCV & 1 & \\
DiverseCV & 10 & \\
\hline
\end{tabular}

model, assuming a uniform spatial distribution of albatrosses. Not surprisingly, bycatch was predicted to be lower under the uniform distribution hypothesis. Brothers et al. (1997) used band sightings to determine shy albatross D. cauta cauta distribution, but could only make general inference about overlap with longline fishing. These studies clearly indicate that assumptions about the underlying pattern of albatross distribution can have a marked impact on inferences about fishery interaction-a result echoed in our analyses - and that more detailed data on albatross distribution and abundance is needed.

More recent studies have used satellite tags to track detailed individual movement with regard to fishery overlap (Birdlife International 2004). For example, Gremillet et al. (2000) deployed geolocators on 32 foraging trips of black-browed albatrosses Diomedea melanophris and found minor overlap with international fisheries operating on the Patagonian shelf for incubating birds and considerable overlap for postbreeding birds. Hyrenbach \& Dotson (2003), using the mean number of hours that 4 satellite-tagged blackfooted albatrosses Phoebastria nigripes spent in $1^{\circ}$ cells, found no overlap with Japanese longliners. Cuthbert et al. (2005) tracked 38 endangered Tristan albatrosses $D$. dabbenena via satellite and found no correlation between at-sea distribution of birds and Japanese eastern Pacific longline fishing effort in $5^{\circ}$ cells. Tagging studies, while providing detailed movement information on individuals, are hampered by sample size and temporal coverage, such that both the absence of apparent overlap as well as degree of overlap should be interpreted with caution.

The spatial interpolation method used in this study was sensitive to highly aggregated albatross sightings. This skewed both the sum and, especially, mean overlap scores such that certain sectors (e.g. DiverseCP) stood out, even if the majority of their effort was in low albatross areas. If hotspots are ephemeral events, especially fishery-induced, rather than persistent biophysical associations, then this method may incorrectly assign risk to fishery sectors, especially those with a broad geographic distribution, such that some overlap is inevitable.

The bathymetric contour method smoothed out the effect of highly aggregated sightings by modeling sightings as a function of distance from the shelf break. The association between short-tailed albatrosses and shelf breaks has been previously noted (Piatt et al. 2006). In an independent study, Suryan et al. (2006) also found satellite-tagged short-tailed albatrosses predominantly over shelf breaks and slopes during late spring to fall. In Alaskan waters, tagged albatrosses spent the majority of their time along the northern Bering Sea shelf break as well as in the passes of the central and western Aleutian Islands. Indeed, seabird hotspots are known to be associated with permanent topographic features (Yen et al. 2004), as well as with ephemeral features such as eddies and fronts (Jahncke et al. 2005, Yen et al. 2006). The bathymetric contour method captured the predominant bio-physical association, but discounted finer-scale features, such as persistent hotspots within the shelf break zone. However, it also minimized the effect of single, remote sightings, which were more likely to be a bird in transit rather than a permanent hotspot (Suryan et al. 2006). In the absence of detailed information about the spatial and temporal distribution of short-tailed albatrosses within Alaska and throughout the North Pacific, methods that capture a persistent underlying bio-physical association are precautionary. However, this simple distanceweighted model could be refined with additional sightings and/or telemetry data that capture finer scale persistent hotspots.

Although fishing in areas of relatively high predicted albatross density was clearly important in determining overlap scores, total effort within the sector influenced scoring. Large amounts of effort boosted sum overlap 
scores such that sectors with lower mean scores ranked higher than sectors with higher mean scores (e.g. PollockCV versus PollockCP-Meal during summer using both albatross prediction methods). However, high effort, in and of itself, was not a sufficient precondition for high sum overlap scores. Sectors with intermediate effort during a season in which other sectors had lower effort but higher mean scores, or the reverse, produced low sum scores (e.g. DiverseCV during spring, summer, and fall using the bathymetric contour method).

With regard to management of non-target species interactions, overlap metrics (i.e. mean versus sum scores) provide complementary information. For instance, sectors with high mean overlap scores may represent opportunities for targeted mitigation research, as these vessels are most likely to encounter albatrosses. On the other hand, sectors with high sum overlap scores may be the most efficacious targets for quickly reducing overall chance of interaction, even if the individual vessel interaction rate is low. However, because interactions or even sightings in sectors with a low mean but high sum overlap score will be rare, fishers may experience bycatch as a non-issue (Melvin \& Parrish 2001).

Finally, the risk of an interaction leading to an albatross mortality is influenced not only by the extent of spatial and temporal overlap, but also by fisheryspecific gear type, vessel operators, the seasonality of seabird assemblages present, and the duration and type of discards (Dietrich 2003, Sullivan 2004). In general, the CV sectors do not discharge offal, and should therefore attract the fewest birds. On the other hand, discharge of offal from vessels in the CP sectors is a known attractant to scavenging seabirds (Sullivan et al. 2006). Within the Alaska groundfish trawl fleet, E. Melvin et al. (unpubl. data) found that a catcherprocessor with a fish meal plant (PollockCP-Meal sector) was attended by half as many seabirds as a similar vessel without a fish meal plant (PollockCP). The difference was attributed to the higher utilization of the catch and consequently less fish product being discharged on the vessel with the fishmeal plant. Complicating these categorizations is the suggestion that the presence of nearby vessels with high attraction rates for birds can positively influence the number of birds associating with a vessel with otherwise low attraction rates (Gonzalez-Zevallos \& Yorio 2006). Thus, although amount, type, or timing of discharge may be regulated to reduce possible interactions (Sullivan et al. 2006), other factors, such as fine-scale vessel spacing, may not have tractable management options.

Given that the short-tailed albatross population is expanding rapidly (Zador et al. 2008), it is likely that their spatial and temporal overlap with the Alaska groundfish trawl fishery, and indeed with all North
Pacific fisheries, will become more extensive. Thus, their overlap with this fishery will likely continue to be of concern. However, determining overlap is only the first step in successful management of non-target species in the context of ecosystem-based fishery management. Establishing overlap lays the groundwork for directed research to elucidate factors that may influence the rate of interactions in areas where overlap is known to occur and targeting mitigation of bycatch in a more efficacious manner. Accurate assessment of bycatch requires knowledge of the nested interactions that lead from spatial and temporal overlap to incidental mortalities in a fishery.

Acknowledgements. We thank the many observers who worked on board groundfish trawl vessels to collect data. We also thank the many fishers, fisheries observers, biologists, and others who submitted short-tailed albatross identification forms. M. Furuness, M. Hartley, T. Hiatt, and M. Loeffled kindly provided data on the trawl fishery and G. Hunt, the North Pacific Pelagic Seabird Database, and the US Fish and Wildlife Service provided data on albatross sightings. K. Dietrich, A. Edwards, D. DeMaster, N. Hamel, D. Hyrenbach, and E. Melvin participated in helpful discussions and reviews during this research. Comments from 3 anonymous reviewers improved the manuscript. NOAA Alaska Fisheries Science Center, NOAA National Seabird Program, and the University of Washington School of Aquatic and Fishery Sciences provided funding to S.G.Z.

\section{LITERATURE CITED}

AFSC (2005a) North Pacific groundfish observer manual, NOAA Alaska Fisheries Science Center, National Marine Fisheries Service, Seattle, WA

AFSC (2005b) Stock assessment and fishery evaluation report for the groundfish fisheries of the Gulf of Alaska and Bering Sea/Aleutian Islands area: Economic status of the groundfish fisheries off Alaska, 2004, NOAA Alaska Fisheries Science Center, National Marine Fisheries Service, Seattle, WA

Bartle JA (1991) Incidental capture of seabirds in the new Zealand subantarctic squid trawl fishery, 1990. Bird Conserv Int 1:351-359

Birdlife International (2004) Tracking ocean wanderers: the global distribution of albatrosses and petrels. Global Procellariiform Tracking Workshop. Birdlife International, Gordon's Bay

Brothers NP, Reid TA, Gales RP (1997) At-sea distribution of shy albatross Diomedea cauta cauta derived from records of band recoveries and colour-marked birds. Emu 97: 231-239

Croxall JP, Wood AG (2002) The importance of the Patagonian Shelf for top predator species breeding at South Georgia. Aquat Conserv: Mar Freshw Ecosyst 12:101-118

Cuthbert R, Hilton G, Ryan T, Tuck GN (2005) At-sea distribution of breeding Tristan albatrosses Diomedea dabbenena and potential interactions with pelagic longline fishing in the South Atlantic Ocean. Biol Conserv 121: 345-355

Dietrich KS (2003) Factors affecting seabird bycatch in Alaska longline fisheries. MSc thesis, University of Washington, Seattle 
ESRI (2005) GIS and mapping software. Environmental Systems Research Institute, Inc., Redlands, CA. www.esri.com ETOPO2 (2001) 2-minute gridded global relief data (ETOPO2). US Department of Commerce, National Oceanic and Atmospheric Administration, Washington, DC

FAO (2004) Fish, crustaceans, mollusks, etc. Capture production by principal species in 2004. Yearbook of fishery statistics summary tables. Food and Agriculture Organization of the United Nations, Rome

Gonzalez-Zevallos D, Yorio P (2006) Seabird use of discards and incidental capture at the Argentine hake trawl fishery in the Golfo San Jorge, Argentina. Mar Ecol Prog Ser 316:175-183

Grémillet DR, Wilson RP, Wanless S, Chater T (2000) Blackbrowed albatrosses, international fisheries and the Patagonian Shelf. Mar Ecol Prog Ser 195:269-280

Hall MA (1996) On bycatches. Rev Fish Biol Fish 6:319-352

Hyrenbach KD, Dotson RC (2003) Assessing the susceptibility of female black-footed albatross (Phoebastria nigripes) to longline fisheries during their post-breeding dispersal: an integrated approach. Biol Conserv 112:391-404

Jahncke J, Coyle KO, Hunt GL (2005) Seabird distribution, abundance and diets in the eastern and central Aleutian Islands. Fish Oceanogr 14:160-177

Melvin EF, Parrish JK (eds) (2001) Seabird bycatch: Trends, roadblocks, and solutions, vol. University of Alaska Sea Grant, Fairbanks, AK. AK-SG-01-01

Nel DC, Ryan PG, Watkins BP (2002) Seabird mortality in the Patagonian toothfish longline fishery around the Prince Edward Islands, 1996-2000. Antarct Sci 14:151-161

NPFMC (2002) Impacts of the American Fisheries Act. Report to the US Congress and the Secretary of Commerce. Prepared by the Staff of the North Pacific Fishery Management Council, Anchorage, AK

NPPSD (2005) North Pacific pelagic seabird database, shorttailed albatross, Ver. 2005.06.07. U.S.G.S. Alaska Science Center and US Fish and Wildlife Service, Anchorage, AK

Piatt JF, Wetzel J, Bell K, DeGange AR and others (2006) Predictable hotspots and foraging habitat of the endangered short-tailed albatross (Phoebastria albatrus) in the North Pacific: Implications for conservation. Deep Sea Res II 53:387-398

Pikitch EK, Santora D, Babcock EA, Bakun A and others (2004) Ecosystem-based fishery management. Science 305:346-347

Slooten E, Dawson S, Rayment W, Childerhouse S (2006) A new abundance estimate for Maui's dolphin: what does it mean for managing this critically endangered species? Biol Conserv 128:576-581

Sullivan BJ (2004) Falkland Islands plan of action for reducing incidental catch of seabirds in trawl fisheries. Seabirds at Sea Team, Falklands Conservation, Cambridge
Sullivan BJ, Reid TA, Bugoni L (2006) Seabird mortality on factory trawlers in the Falkland Islands and beyond. Biol Conserv 131:495-504

Suryan RM, Sato F, Balogh GR, Hyrenbach KD, Sievert PR, Ozaki K (2006) Foraging destinations and marine habitat use of short-tailed albatrosses: A multi-scale approach using first-passage time analysis. Deep Sea Res II 53: 370-386

Suryan RM, Dietrich KS, Melvin EF, Balogh GR, Sato F, Ozaki K (2007) Migratory routes of short-tailed albatrosses: use of exclusive economic zone of North Pacific Rim countries and spatial overlap with commercial fisheries in Alaska. Biol Conserv 137:450-460

Troëng S, Chacon D, Dick B (2004) Possible decline in leatherback turtle Dermochelys coriacea nesting along the coast of Caribbean Central America. Orynx 38:395-403

> Tuck GN, Polacheck T, Croxall JP, Weimerskirch H (2001) Modelling the impact of fishery by-catches on albatross populations. J Appl Ecol 38:1182-1196

USFWS (2003) Biological opinion on the effects of the total allowable catch (TAC)-setting process for the Gulf of Alaska (GOA) and Bering Sea/Aleutian Islands (BSAI) groundfish fisheries to the endangered short-tailed albatross (Phoebastria albatrus) and threatened Steller's eider (Polysticta stelleri), US Fish and Wildlife Service, Anchorage, AK

USFWS (2005) Short-tailed albatross draft recovery plan, US Fish and Wildlife Service, Anchorage, AK

Weimerskirch H, Brothers N, Jouventin P (1997) Population dynamics of wandering albatross Diomedea exulans and Amsterdam albatross $D$. amsterdamensis in the Indian Ocean and their relationships with long-line fisheries: conservation implications. Biol Conserv 79:257-270

Weimerskirch H, Capdeville D, Duhamel G (2000) Factors affecting the number and mortality of seabirds attending trawlers and long-liners in the Kerguelen area. Polar Biol 23:236-249

Wilson B, Rivera K, Fitzgerald S, Rose C (2004) Discussion paper on seabird interactions with trawl vessel gear. Report No. 2, North Pacific Fishery Management Council, Anchorage, AK

> Yen PPW, Sydeman WJ, Hyrenbach KD (2004) Marine bird and cetacean associations between bathymetric habitats and shallow-water topography: implications for trophic transfer and conservation. J Mar Syst 50:79-99

$>$ Yen PPW, Sydeman WJ, Borgrad SJ, Hyrenbach KD (2006) Spring-time distributions of migratory marine birds in the southern California Current: oceanic eddy associations and coastal habitat hotspots over 17 years. Deep Sea Res II 53:399-418

Zador SG, Punt AE, Parrish JK (2008) Population impacts of endangered short-tailed albatross bycatch in the Alaskan trawl fishery. Biol Conserv 141:872-882 
Appendix. Relative overlap scores as calculated from the overlap of trawls with albatross distributions predicted using the spatial interpolation method and bathymetric contour methods. Highest scores within a season are in boldface type.

\begin{tabular}{|lcccc|}
\hline Season & \multicolumn{2}{c}{ Spatial interpolation } & \multicolumn{2}{c|}{ Bathymetric contour } \\
Sector & $\begin{array}{c}\text { Mean } \\
\text { overlap score }\end{array}$ & $\begin{array}{c}\text { Sum } \\
\text { overlap score }\end{array}$ & $\begin{array}{c}\text { Mean } \\
\text { overlap score }\end{array}$ & $\begin{array}{c}\text { Sum } \\
\text { overlap score }\end{array}$ \\
\hline Winter & & & & \\
PollockCP-Meal & 0 & 5616 & $\mathbf{0 . 0 1}$ & $\mathbf{7 6 1 9}$ \\
PollockCP & 0.01 & 5970 & 0 & 4823 \\
DiverseCP & 0.03 & 129823 & 0 & 7455 \\
PollockCV & 0.1 & 459718 & 0 & 4828 \\
DiverseCV & $\mathbf{0 . 3 1}$ & $\mathbf{1 0 9 6 4 5 0}$ & 0 & 2599 \\
Spring & & & & \\
PollockCP-Meal & 0.14 & 135618 & 0.06 & 54789 \\
PollockCP & 0.47 & 385298 & $\mathbf{0 . 0 9}$ & 69774 \\
DiverseCP & 0.58 & 3850607 & 0.05 & $\mathbf{3 1 3 0 0 0}$ \\
PollockCV & 0.44 & 2305075 & 0.03 & 146340 \\
DiverseCV & $\mathbf{0 . 8 1}$ & $\mathbf{4 3 8 5 8 8 5}$ & 0.03 & 52987 \\
Summer & & & & \\
PollockCP-Meal & 2.46 & 3892781 & 0.28 & 445453 \\
PollockCP & 1.92 & 2555019 & $\mathbf{0 . 2 9}$ & 386356 \\
DiverseCP & $\mathbf{2 . 6 8}$ & $\mathbf{1 6 6 1 7 7 8 8}$ & 0.18 & $\mathbf{1 1 2 9 1 1 6}$ \\
PollockCV & 1.51 & 9324678 & 0.09 & 551712 \\
DiverseCV & 1.79 & 5682892 & 0.18 & 168833 \\
Fall & & & & \\
PollockCP-Meal & $\mathbf{4 . 8 9}$ & $\mathbf{5 8 0 5 0 0 0}$ & $\mathbf{0 . 1 3}$ & 153630 \\
PollockCP & 2.67 & 2236321 & 0.10 & 83982 \\
DiverseCP & 0.50 & 2298803 & 0.06 & 275484 \\
PollockCV & 0.86 & 5296761 & 0.08 & $\mathbf{5 0 1 4 7 7}$ \\
DiverseCV & 1.23 & 3387374 & 0.07 & 61561 \\
& & & & \\
\hline
\end{tabular}

Editorial responsibility: Rebecca Lewison, San Diego, California, USA
Submitted: September 26, 2007; Accepted: September 26, 2008 Proofs received from author(s): November 15, 2008 